\title{
Representaciones de la mujer en la prensa escrita: análisis de contenidos diario Correo
}

\author{
Representations of women in the written press: \\ daily content analysis Mail
}

Génenis Gárces Ortíz Universidad Técnica de Machala Machala - Ecuador gagarces_est@utmachala.edu.ec

Karol Gálvez Palomeque Universidad Técnica de Machala Machala - Ecuador kgalvez@utmachala.edu.ec

Diana Viveros Aguilar Universidad Técnica de Machala Machala - Ecuador dviveros@utmachala.edu.ec

Rúben Zapata Chacón Universidad Técnica de Machala Machala - Ecuador rpzapata@utmachala.edu.ec

Revista Cumbres Vol.5 №1

Versión impresa ISSN 1390-9541

Versión electrónica ISSN 1390-3365

http://investigacion.utmachala.edu.ec/revistas/index.php/Cumbres 


\section{RESUMEN}

En esta época, la participación de la mujer es tan importante como la del hombre y a pesar de haber alcanzado varios logros, estos no se visibilizan del todo. La discriminación también es violencia de género y los diarios siguen excluyendo a la mujer de varios ámbitos y la destacan como sinónimo de belleza y debilidad. Los periódicos son constructores de la realidad social y generan modelos sobre el "deber ser" o el "deber seguir". Por ello, el objetivo planteado fue determinar la representación de la mujer en las notas periodísticas publicadas por diario Correo, en uno de los meses con alto índice de femicidios. Para esto, se realizó un análisis de las notas periodísticas, para saber si ¿̇la mujer es violentada y estereotipada en la prensa?

Algunos de los resultados fueron que la mujer tiene el 19\% de participación en las noticias locales; de esa cifra, en el 67\% es protagonista y, en su mayoría, no está marcada por estereotipos de género. Sin embargo, en un $24 \%$ es destacada por su "cuerpo" o por alguna "conducta transgresora". La mujer sigue siendo discriminada en algunas secciones y su participación es mínima en los espacios informativos, en comparación con el hombre.

Palabras clave: Violencia de género, Estereotipos de género, Prensa, Mujer.

\section{ABSTRACT}

At this time, the participation of women is as important as that of men and despite having achieved several achievements, these are not visible at all. Discrimination is also gender violence and newspapers continue to exclude women from various fields and highlight it as a synonym of beauty and weakness. Newspapers are builders of social reality and generate models on the "must be" or the "must follow". Therefore, the objective was to determine the representation of women in the newspaper articles published by daily newspaper Correo, in one of the months with high femicide rates. For this, an analysis of the journalistic notes was made, to know if the woman is misinterpret and stereotyped in the press?

Some of the results were that women have 19\% participation in local news; of that figure, $67 \%$ are protagonists and, for the most part, they are not marked by gender stereotypes. However, in $24 \%$ it is highlighted by its "body" or by some "transgressive behavior". Women continue to be discriminated against in some sections and their participation is minimal in the information spaces, in comparison with men.

Keywords: Gender violence, Gender Stereotyping, Gender Stereotypes, Press, Woman.

\section{Cumbres}




\section{INTRODUCCIÓN}

El rol de la mujer, históricamente, ha estado inmerso en una sociedad patriarcal, donde el protagonismo político, social, económico y de toda índole está siempre liderado por la imagen del hombre dominante, fuerte, racional y de características vinculadas a la vida pública.

En ese ámbito, el rol de la mujer ha quedado en segundo plano, se ha visto "disminuido", "reducido" a la sombra del sexo masculino o "menospreciado", si se quiere decir, a actividades estrictamente relacionadas a la vida privada, doméstica o familiar.

Pero, estas consideraciones históricas no deberían sorprender, ya que forman parte de un proceso de evolución que durante siglos la mujer ha sido capaz de cambiar con su lucha constante por la igualdad de derechos.

Hoy en día, la participación de la mujer en la esfera pública es tan importante como la de un hombre, así lo demuestran las leyes de diferentes países y así también lo demuestran las votaciones democráticas que designan presidentas de Estado, asambleístas, alcaldesas, etc.

Sin embargo, estos nuevos papeles que desempeña la mujer y los estereotipos en general, que giran en torno a las características femeninas, ¿También cambiaron en la representación que hacen los medios impresos? La respuesta a simple vista debería ser que sí, ya que los medios de comunicación construyen justamente la realidad social en base a hechos actuales. Los cambios en la percepción ciudadana de los roles femeninos deberían estar también representados en los medios impresos. Pero, esas variaciones de los patrones socioculturales en los contenidos periodísticos son precisamente el objetivo de análisis en esta investigación.

Los estereotipos contra la mujer también son una forma de discriminación, que posteriormente puede acarrear violencia. Bourzac, Portuondo \& Agüero. (2016:87) afirman: "dado el estereotipo genérico construido desde la antigüedad sobre la mujer, esta ha sido objeto de discriminaciones, violencias, rechazos y exclusiones".

Los medios de comunicación, por medio de la información que presentan visibilizan la violencia contra la mujer, no solo mostrada por estereotipos y roles sino también invisibilizándola, lo cual se considera discriminación, una forma de violencia. (Jorge, 2016)

Estos estereotipos pueden ser visibles en las notas periodísticas a través de ciertas formas de redacción de las noticias o representación de las imágenes. Para esta investigación se tomará como referencia únicamente uno de los diarios locales más vendidos en la provincia de El Oro, diario Correo, en el cual se analizará: ¿Cómo son representadas las mujeres en las notas periodísticas del diario impreso Correo de la ciudad de Machala?

Con el afán de identificar si la participación de la mujer dentro de los medios impresos es violentada o no, mediante el uso de los estereotipos de género o simplemente descubrir el protagonismo que se le da en las apariciones que ésta tiene dentro de las notas periodísticas del medio impreso, haciendo visible la teoría de que a la mujer solo se la relega a temas de la 
esfera privada, profundizando en los conceptos de violencia contra la mujer y aclarando que las lesiones físicas y los gritos no son el único tipo de violencia que se realiza contra la mujer

\section{DESARROLLO CONCEPTUAL}

\section{Estereotipos de Género contra las mujeres}

Los estereotipos, según Laird \& Thompson (1992) (citados por Colás \& Villaciervos, 2007:38) son: "generalizaciones preconcebidas sobre los atributos o características de la gente en los diferentes grupos sociales". Es decir que la sociedad atribuye o resalta particularidades que pueden poseer o no en su físico o manera de actuar, prejuicios creados a partir de sus ideologías.

Los seres humanos están regidos por "controles" que establecen el comportamiento que debe tener un individuo y recriminan si estos actúan de forma contraria a lo que se espera o dicta la cultura en la que se desarrolla. Autores como Colás \& Villaciervos (2007:38) explican: “desde la perspectiva sociocultural estas representaciones son internalizadas por los sujetos que forman parte de dicha cultura, estructurando y configurando formas de interpretar, actuar y pensar sobre la realidad".

Debido a la cultura patriarcal, el papel de la mujer resulta relegado ante la figura masculina, y modelos de "deber ser" o "deber seguir" son dictaminados por los medios de comunicación. Comúnmente se observa a la mujer como objeto de belleza o deseo, la típica ama de casa o la "machona" por no saber cocinar o ser partícipe de una actividad que "solamente" concierne a los hombres. La mujer es duramente criticada y llena de restricciones en comparación con el hombre, así lo reafirman Castrillón \& López (2016:30):

La sociedad determina que la mujer como un ser pasivo ante las decisiones, debe ejercer exclusivamente labores que le son asignadas en los espacios de la vida privada, negándoseles una participación en lo público. Toda actividad que estuviera por fuera de lo establecido se entendía como una transgresión. Frente a estas conductas transgresoras la prensa cumplía un papel de señalamiento y de juzgamiento

García, Aguaded \& Rodríguez (2014:580) manifiestan que: “tradicionalmente se han considerado positivos los rasgos masculinos, mientras que los femeninos son considerados negativos. (...)". Y ¿cómo no? Si el hombre es el fuerte, el que debe y tiene el conocimiento y toda la potestad de decidir y opinar sobre los temas importantes concernientes al país y también en el hogar, la mujer por el contrario según Castrillón \& López (2016:30-31):

El deber ser de la mujer implica el cumplimiento de sus funciones en las actividades de madre, esposa, cuidadora y mujer pura; por el contrario, el no deber ser se relaciona con los comportamientos transgresores, asociados al ser pecadora, fácil, prostituta y mujer fatal.

Ortega (1998) (citado por Colás \& Villaciervos, 2007) separa los estereotipos de género en cuatro categorías: el cuerpo, capacidades intelectuales,

\section{Cumbres}


dimensión afectiva y emocional y relaciones e interacciones sociales (comunicación interpersonal), en ese orden Colás \& Villaciervos (2007: 38-39) manifiestan que:

Las denotaciones corporales expresadas socialmente a través del arte y de los medios de comunicación, entre otros, son interiorizadas por los individuos conformando la imagen del cuerpo masculino en torno a la fuerza y el vigor, y la imagen del cuerpo femenino en torno a la delicadeza y debilidad (...) la moral femenina se construye en base a un control continuo del cuerpo y de sus expresiones bajo la presión continua de la moral y la vigilancia del pudor. (...) Se asigna un mejor desempeño masculino en tareas técnicas, mecánicas y manuales; mientras que al género femenino se le atribuyen mayores habilidades organizativas y cooperativas. (...) mayor afectividad y emotividad al género femenino y un mayor control emocional el género masculino.

Siempre se le dijo a la mujer, desde niña que debía preocuparse por su físico, ser tierna, respetuosa y delicada, debía ser defendida de los demás, aprender a cocinar, lavar y limpiar además de ser la encargada de criar y cuidar, por lo tanto sus juguetes fueron: las muñecas, los utensilios de cocina y limpieza. En cambio a los varones se les enseña a ser rudos, saber cuidar a las niñas indefensas y no preocuparse de nada por lo tanto sus juguetes fueron los carros.

Este tipo de pensamiento también se refleja en los espacios publicitarios, y se refuerza con lo mencionado por Francke \& Ojeda (2013:369) sobre el dominio que la publicidad tiene en la sociedad, por lo tanto ésta: “(...) sigue reproduciendo los estereotipos de género tradicionales, vinculando, por ejemplo, a las mujeres a productos de limpieza y cocina, al tiempo que los hombres aparecen ligados a los negocios y al trabajo asalariado (...)".

Simón (2005) (citado por Colás \& Villaciervos, 2007:40) señala que: "las niñas perciben alrededor de la pubertad que su éxito va a ir unido sobre todo a su belleza y en el mejor de los casos a su simpatía". Un concepto que acentúa el pensamiento inmerso en la sociedad, donde se le da mucho mas valor al aspecto físico de la mujer que al intelectual.

No es negativo que el género femenino se preocupe por la crianza de los hijos, expresar afecto y tolerancia a los demás. Lo negativo es que se la quiera encasillar simplemente a un lugar.

La mujer aún es representada en el rol de reproducción de la vida doméstica, la madre virtuosa y la esposa fiel y cuidadora, las conductas femeninas que transgreden estas pautas son condenadas social y mediáticamente. (...) como alguien que se buscó su trágico destino con su comportamiento (...). Estigmatización de la víctima con frases como "se vestía o bailaba muy provocativamente", lo que implica deslizarse hacia la culpabilidad de la víctima que se convierte en "merecedora de la agresión". (Cremona, Rosales \& Actis, 2013:9-10)

La mujer al igual que el hombre es un ser humano, ambos tan iguales y distintos a la vez y deberían poseer derechos y libertad a destacarse en el ámbito de su preferencia y en las actividades que mejor les parezca sin miedo a ser criticados o condenados.

El hombre es protagonista importante en todos los ámbitos, y ocupador de todos los espacios, claramente podemos visibilizar esta realidad en el ám- 
bito deportivo. Bruce (2009), O’Neill \& Mulready (2015) (citados por Gómez, Medina \& Ramon, 2017:795) aseguran que: "el periodismo deportivo se ha construido como un territorio predominantemente masculino, donde las desigualdades de género se han legitimado y acentuado".

Baranda (2013) (citado por Gómez, Medina \& Ramon, 2017:795) explica como resultado de su tesis doctoral que:

Las informaciones sobre mujeres deportistas no tienen la relevancia suficiente para considerarse tema principal; y distingue dos perfiles de mujeres en la prensa deportiva: las que son propias del ámbito deportivo (...) y las "invitadas" (...) Estas últimas son las familiares, parejas, famosas o aficionadas que toman -o se les adjudica- el papel de acompañantes reforzando, de esta manera, los estereotipos de la mujer objeto o elemento decorativo.

\section{Violencia de Género contra la mujer}

Maqueda (2006) (citado por Menéndez, 2013:55) expresa que la violencia de género es la: "consecuencia de una situación de discriminación intemporal que tiene su origen en una estructura social de naturaleza patriarcal". Cultura que muestra a la mujer como un ser inferior al hombre. La mujer tiene el deber de someterse a las órdenes y caprichos del sexo masculino, esto se ha vuelto un hábito inculcado por las madres de varias generaciones; tanto así que pasamos este hecho desapercibido o como algo normal y natural. Así lo afirma Maqueda (2006:6): "Son patrones culturales tan enraizados en la sociedad que han terminado por normalizarse, por considerarse "naturales".

La transmisión que los medios de comunicación, y en concreto la prensa, hacen de este fenómeno puede resumirse en una violencia circunscrita a lo íntimo y afectivo, a la relación de pareja (...) y anclada al ámbito de las agresiones físicas con o sin resultado de muerte (...). (Zurbano \& Liberia, 2014:134)

Guardaras (2016:192) afirma que: "la violencia de género se ha construido como problema social a partir de ciertos discursos, prácticas y relaciones sociales". La violencia de género contra la mujer es un problema que aqueja constantemente a la sociedad y que aún no se ha logrado identificar con claridad "por la falta datos y de estudios con muestras probabilísticas sobre formas de violencia distintas a la violencia de pareja" (Frías, 2014:15). Si conversamos con alguien acerca de este tema definirá a la violencia como el acto de golpear a alguien, no todos saben reconocer que la violencia se presenta de diversas formas (laceraciones, insultos que limitan la libertad de pensar o realizar determinada acción) y en las diferentes esferas: pública (temas políticos y de economía), privada (temas de moda, belleza y hogar); lo corrobora la legislación Argentina (2009) (citado por Zurbano y Liberia, 2014:133) conceptualiza el término de violencia de género como:

Toda conducta, acción u omisión que de manera directa o indirecta, tanto en el ámbito público como en el privado, basada en una relación desigual de poder, afecte su vida, libertad, dignidad, integridad física, psicológica, sexual, económica o patrimonial, así como también su seguridad personal (...) desde el Estado o por sus agentes. Incluyendo la violencia de tipo mediática" 


\section{Teoría o Agenda del Framing en la prensa}

Tankard citado por Aruguete (2011:70) define a la Agenda Framing como: "una idea central organizadora del contenido informativo que brinda un contexto y sugiere cuál es el tema mediante el uso de la selección, el énfasis, la exclusión y la elaboración”. Lo que hace pensar que "(...) los medios no solo informan, sino que también son constructores de representaciones sobre los fenómenos sociales" (Angélico, Dikenstein, Fischberg \& Maffeo,

2014:287)

"Cualquier texto comunicativo, ya sea informativo o persuasivo, requiere de estructuras narrativas que organicen el discurso" (Ardèvol, 2015:424). En los medios de comunicación el emisor selecciona qué y cómo contar el acontecimiento, por lo tanto tiene la libertad de colocar o sacar frases que él crea conveniente omitir o añadir. De esta manera se vincula el mensaje a la mente del lector interviniendo en su forma de ver, actuar y pensar Entman (1993) (citado por Ardèvol, 2015:424) asegura que:

El encuadre o framing puede definirse como un proceso en el que se seleccionan algunos aspectos de la realidad, a los que les otorgará un mayor énfasis o importancia, de manera que se define el problema, se diagnostican sus causas, se sugieren juicios morales y se proponen soluciones y conductas apropiadas a seguir.

Según Metz Galán (2016: 300), "los estereotipos de género son una de las principales fuentes de obstáculos que enfrentan las mujeres para lograr su desarrollo pleno, por eso es necesario conocer los modelos de feminidad que difunde esta industria cultural".

\section{MATERIALES Y MÉTODOS}

En el siguiente trabajo se utilizó los métodos: cualitativo, cuantitativo y bibliográfico. Mediante una entrevista aplicada a los señores Hugo Chuico, Jefe de redacción del Diario Correo y Luis Becerra. Redactores del Diario Correo.

Para el análisis de contenido de las notas periodísticas se elaboró dos fichas de observación. La primera recoge datos sobre la cantidad de hechos noticiosos y luego se procede a indicar en cuántos tiene protagonismo la mujer e igual con el hombre.

Tabla 1. Modelo de ficha de observación

\begin{tabular}{|l|}
\hline Día y Fecha \\
\hline Número de notas periodísticas \\
\hline Número de protagonistas mujeres \\
\hline Número de protagonistas hombres \\
\hline Otros \\
\hline
\end{tabular}

La segunda plantilla busca señalar el nivel de protagonismo que se le ofrece a la mujer en las publicaciones noticiosas, el rol que cumple dentro de éstas, las secciones en la que destaca, conocer en qué esfera se desenvuelve: pública o privada, esto de acuerdo al autor Castoriadis (2006:91) que explica de la 
esfera pública que: "en realidad no es pública en absoluto, pues constituye la propiedad del Aparato totalitario que detenta y ejercita el poder" y de la esfera privada dice "es el campo en el que, formalmente y como principio, el poder ni puede y ni debe intervenir, aunque, como es usual en este campo, eso ni puede y ni debe entenderse en sentido absoluto" (Castoriadis, 2006:91).

Para verificar la existencia de estereotipos inmersos en las publicaciones se basa en la información bibliográfica recogida por los autores Colás \& Ciervos (2007) donde Ortega clasifica los estereotipos de género en cuatro categorías: "Cuerpo", "Dimensión afectiva o emocional", "Capacidad Intelectual" y "Relaciones e interacciones sociales"; otro parámetro a considerar es el propuesto por Castrillón y López: “Conducta Transgresora” relacionada al "no deber ser" de la mujer; en caso de no cumplirse con ningún tipo de estereotipo existe un puntos para especificar que no se aplican adjetivos a la mujer. Igualmente se procede con el análisis fotográfico que acompaña a la noticia.

Tabla 2. Modelo de ficha de observación

\begin{tabular}{|c|c|c|c|}
\hline \multicolumn{3}{|l|}{ Día y fecha } & \\
\hline \multicolumn{3}{|l|}{ Título de la noticia } & \\
\hline \multicolumn{3}{|c|}{ 1. ¿Qué participación tiene la mujer en la noticia? (Si la mujer no es protagonista pasar al punto 8) } & \\
\hline \multicolumn{3}{|l|}{ Es protagonista } & \\
\hline \multicolumn{3}{|l|}{ Es secundaria } & \\
\hline \multicolumn{3}{|l|}{ Es un complemento } & \\
\hline \multicolumn{3}{|c|}{ 2. Nombre de la mujer protagonista } & \\
\hline & & & \\
\hline \multicolumn{3}{|c|}{ 3. ¿Por qué se destaca? } & \\
\hline & & & \\
\hline \multicolumn{4}{|c|}{ 4. ¿En qué sección se habla de la mujer? (Solo si la mujer es protagonista) } \\
\hline Ciudad & & $\begin{array}{l}\quad \text { In- } \\
\text { ternacio- } \\
\text { nales }\end{array}$ & \\
\hline Medicina & & $\begin{array}{r}\text { Ac- } \\
\text { tualidad }\end{array}$ & \\
\hline Deportes & & $\begin{array}{l}\text { Can- } \\
\text { tonal o } \\
\text { Cantona- } \\
\text { les }\end{array}$ & \\
\hline Intercultural & & $\begin{array}{l}\text { Va- } \\
\text { rios }\end{array}$ & \\
\hline Sucesos & & País & \\
\hline Espectáculos & & $\begin{array}{l}\text { Eco- } \\
\text { nomía }\end{array}$ & \\
\hline \multicolumn{3}{|c|}{ 5. ¿En qué esfera es representada la mujer? } & \\
\hline Esfera pública & & $\begin{array}{l}\text { Es- } \\
\text { fera } \\
\text { privada }\end{array}$ & \\
\hline
\end{tabular}


6. ¿A qué categoría de estereotipo de género pertenece la característica que se destaca de la mujer en la nota?

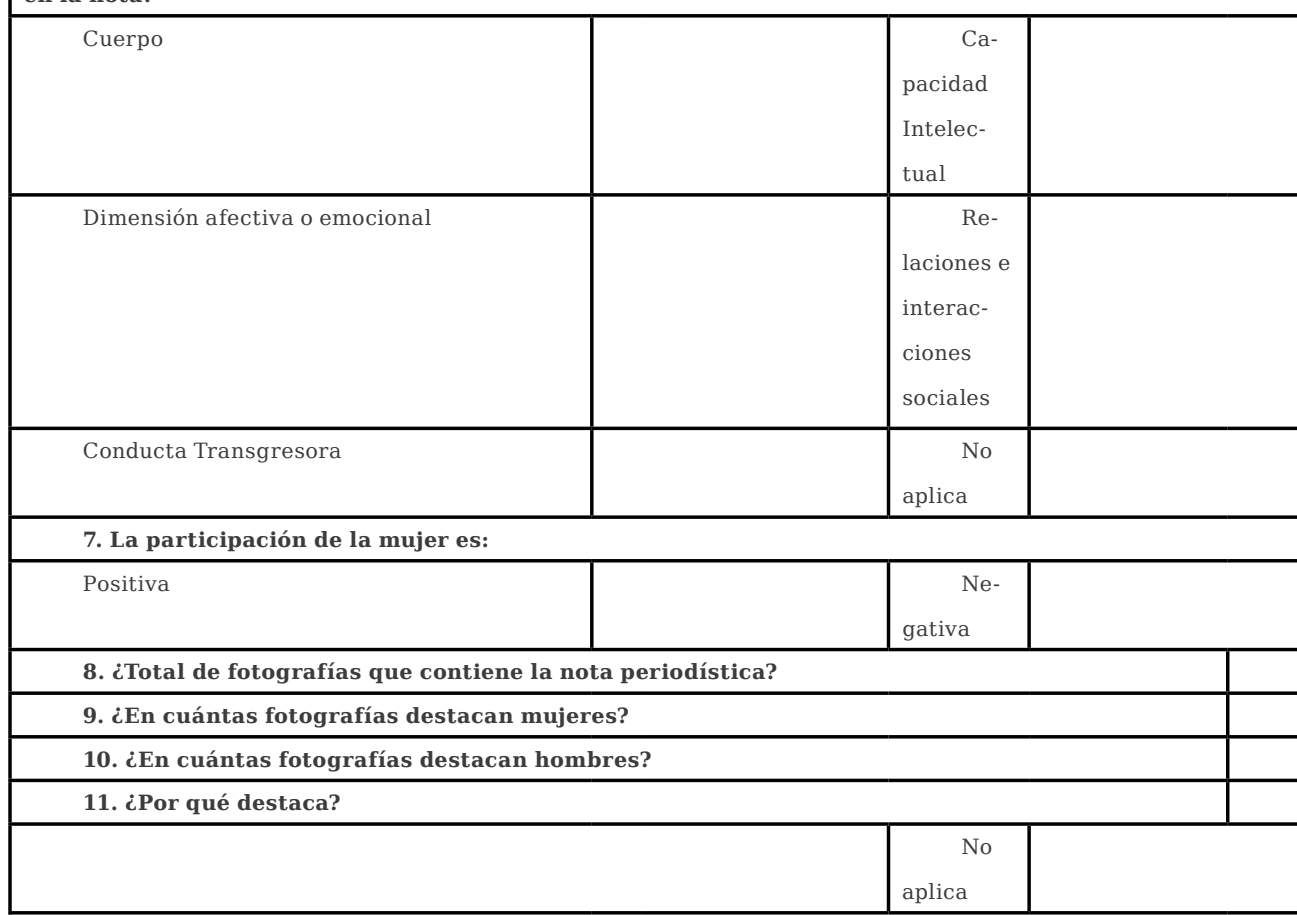

12. ¿A qué categoría de estereotipo de género pertenece la característica que se destaca de la mujer en la fotografía? (Si la mujer es protagonista o no)

\begin{tabular}{|c|c|c|c|}
\hline Cuerpo & & $\begin{array}{l}\quad \text { Ca- } \\
\text { pacidad } \\
\text { Intelec- } \\
\text { tual }\end{array}$ & \\
\hline Dimensión afectiva o emocional & & $\begin{array}{l}\quad \text { Re- } \\
\text { laciones e } \\
\text { interac- } \\
\text { ciones } \\
\text { sociales }\end{array}$ & \\
\hline Otros estereotipos & & $\begin{array}{l}\text { No } \\
\text { aplica }\end{array}$ & \\
\hline \multicolumn{4}{|c|}{ 13. La participación de la mujer es: } \\
\hline Positiva & Negativa & & No aplica \\
\hline
\end{tabular}

Para este estudio se escogió al Diario Correo por ser un periódico de circulación provincial, muy reconocido en la ciudad de Machala y la provincia de "El Oro", además de presentar mayor número de tiraje. Se seleccionó como muestra quince diarios impresos correspondientes a los primeros quince días de noviembre por encontrarse entre dos meses con mayor índice de femicidios "Tenemos un pico de homicidios en el mes de marzo 2015, mes en el cual el número de femicidio se mantiene igualmente alto. Idéntico comportamiento ocurre en el mes de diciembre y octubre de 2014" (Argüelo, Peralta, Tupiza, Marcandalli \& Andrade, 2016:41). 
De estos se tomó en cuenta las secciones: Ciudad, Medicina, Deportes, Intercultural, Sucesos, Espectáculos, Internacionales, Actualidad, Cantonal o Cantonales, Varios, País, Economía y Reportaje; por tratarse de secciones dedicadas netamente a la redacción de hechos noticiosos. Por centrar el análisis únicamente a las notas periodísticas se excluyen las secciones que contienen únicamente fotografías, publicidad, necrologías y reseñas históricas y aquellas en las que se vierte la opinión del escritor como: Editoriales, Fecha cívica, Clasificados, Miscelanea, Necrológicas, Viernes Social. Los segmentos: Foto del día y Correo gráficas. Igualmente los suplementos: Tendencias, Suplemento Especial y Hora libre; debido a que su circulación no es diaria.

\section{RESULTADOS}

La investigación refleja, mediante el análisis de la fichas de observación, que la participación de la mujer es del 19\% del total de notas periodísticas las publicaciones en diario Correo de la Ciudad de Machala, durante los quince primeros días del mes de noviembre del 2017 en comparación con la participación que tiene el hombre $73 \%$, en donde la mujer tiene un porcentaje minoritario.

De acuerdo a las notas en donde la mujer protagoniza se encuentra en que en el $67 \%$ es el personaje principal de la redacción, como personaje secundario se la considera en un $17 \%$ y con $16 \%$ se la encuentra como un complemento.

Los hechos noticiosos que protagoniza la mujer en su mayoría (65\%) no se encuentran marcados por estereotipos de género. Sin embargo, en aquellas redacciones donde se hacen presentes estereotipos de género, se reflejan características pertenecientes a la categoría de: "cuerpo" (belleza, delicadeza y debilidad) con 15\%; la "conducta transgresora" relacionada al "no deber ser" de la mujer con un 9\%. Estereotipos de "Capacidad Intelectual" resaltan con 6\% "dimensión afectiva o emocional" obtienen un $5 \%$. Aquellas características de "Relaciones e Interacciones sociales" no se usan en ninguna de las noticias.

En relación a las secciones pertenecientes al periódico Correo donde el género femenino tiene mayor aparición están: “Ciudad”, "Actualidad”, "Cantonal o Cantonales" y "Sucesos"; mientras que en las secciones donde menos visible es la mujer, se encuentran: "Deportes", "Intercultural”, "Medicina”, "Varios", "Espectáculos", "Economía” y "Reportaje”. Destacando que el número de secciones en las que menos intervención tienen las mujeres son mayoría.

Respecto al papel que la mujer desempeña en las redacciones se determina: que el $22 \%$ de las mujeres protagonistas destacan por cargos privados (emprendedoras, gerentes o representantes de empresas privadas), el 20\% desempeñan cargos políticos (gobernaciones, alcaldías, asambleístas y presidencias barriales o dentro de movimientos políticos y agrupaciones). El 15\% provienen del mundo artístico (actrices y cantantes), un $10 \%$ son victimarias 
(robos y estafas y acoso). Las mujeres deportistas simbolizan un 6\% y solamente un $3 \%$ es un complemento.

Tomando en cuenta únicamente las publicaciones en que la mujer es personaje principal se determina que, su participación es elevada en la esfera privada (aquella relacionada al poder) con $70 \%$ en comparación con la esfera pública (aquella en la que el poder externo no ingresa) que tiene un $30 \%$.

En las publicaciones en donde la mujer es protagonista se encuentra que no en todas las fotos de las notas aparece el genero femenino, siendo el 57\% en las que aparece solo la imagen de la mujer, en el 18\% aparecen hombres y mujeres y en el $21 \%$ aparecen solo hombres. Cabe mencionar que en ciertas redacciones donde la mujer era la protagonista aparecían fotografías de hombres y en los hechos noticiosos donde se hallaba al hombre como principal tenían fotografías de féminas.

El rol que mayoritariamente cumple la mujer dentro de las fotografías con el $22 \%$ son los cargos políticos (cabe destacar que en esta fecha del análisis una mujer ostenta un cargo público importante a nivel provincial). En el mismo porcentaje de $22 \%$ son cargos privados seguidos por los reinados con un $21 \%$. Con un $20 \%$ de las mujeres son artistas de diversa índole. Funcionarias públicas son visibilizadas en un 5\% y el $6 \%$ engloba a deportistas de genero femenino. Víctimas y victimarias se observan con similar porcentaje, $2 \%$. Ninguna es vista como complemento.

El diario en $64 \%$ no transmite estereotipos en sus fotografías. Los estereotipos de género mayormente usados en las fotografías que hacen aparición en el medio impreso "Correo" son aquellos direccionados al "cuerpo" con un $24 \%$, destacando más los atributos físicos frente a otros. Mientras los de "Dimensión afectiva o emocional" están en un 7\%, los de Capacidad intelectual en $3 \%$, los de "Conducta transgresora" en $2 \%$.

\section{CONCLUSIONES}

La participación de la mujer en el diario Correo es escasa en comparación con los espacios brindados al hombre. Se evidenció que aún es representada con menor importancia, es decir; como la acompañante de su esposo o pareja y en algunos casos de los hijos.

En las fotografías que acompañaban las redacciones en donde la mujer destacaba, aparecían ellas en compañía de hombres y en los hechos noticiosos protagonizados por hombres en la mayoría de las fotos sobresalen hombres y las pocas mujeres que participaban eran modelos o candidatas a reinas y escasamente cumplían roles ganados por su intelecto o capacidad de liderar.

Las notas que contenían estereotipos representaban en altas cantidades a la mujer en reinados de belleza, ocupando el papel de la madre o esposa afligida, que pierde a un hijo o esposo accidentado o asesinado.

El diario Correo otorga menor protagonismo a la mujer, esto es reflejado inclusive en la cantidad de secciones en la que aparece, que son menos en comparación con las secciones en que se la excluye. Respecto a los roles 
que las féminas desempeñan, vemos mayormente a la mujer concursando en eventos de belleza que participando en el ámbito deportivo.

Finalmente, la participación de la mujer es elevada en la esfera privada, donde en algunos casos son ellas las que se abren camino como emprendedoras y empresarias de sus propios negocios, en comparación con la esfera pública a pesar de existir muchas representaciones femeninas dentro de la política y al mando de instituciones públicas.

\section{REFERENCIAS BIBLIOGRÁFICAS}

Aguaded-Gómez, J., Tello-Díaz, J., \& Sánchez Carrero, J, (2011)."Rostros de mujer": Análisis de estereotipos femeninos. Reflexiones, 90 (2), 115-124

Angélico, R., Dikenstein, V., Fischberg, S., \& Maffeo, F. (2014). El feminicidio y la violencia de género en la prensa argentina: un análisis de voces, relatos y actores. Universitas Humanística, 78(78), 281-303. Recuperado de http://revistas.javeriana.edu.co/index.php/univhumanistica/ article/view/6325/8202

Ardévol, A. (2015). Framing o teoría del encuadre en comunicación. Orígenes, desarrollo y panorama actual en España. Revista Latina de Comunicación Social, (70), 423-450. doi: 10.4185/RLCS-2015-1053

Aruguete, N. (2011). Framing. La perspectiva de las noticias. La Trama de la Comunicación, 15, 67-80.

Bourzac, L., Portuondo, M., \& Agüero, G. (2016). Periodismo de las otredades. Una propuesta de práctica decolonizadora. Controversias y concurrencias latinoamericanas, 8(12), 83-84.

Camacho, G. (2014). Violencia de género contra las mujeres en el Ecuador. Quito: El Telégrafo.

Castrillón, C., \& López, L. (2016). Al límite de la violencia de género: representaciones de transgresiones protagonizadas por mujeres en la prensa cartagenera, 1940-1950. La manzana de la discordia, 11(1), 29-39.

Colás, P., \& Villaciervos, P. (2007). La interiorización de los estereotipos de género en jóvenes y adolescentes. Revista de Investigación Educativa, 25(1), 35-58.

Castoriadis, C. (2006). La democracia como procedimiento y régimen. Iniciativa Socialista, 85 - 101.

Cremona, M., Actis, M., \& Rosales, M. (Julio, 2013). Representaciones del cuerpo femenino en el discurso mediático: la experiencia del Observatorio de Medios, Comunicación y Género. X Jornadas de Sociología. Facultad de Ciencias Sociales, Universidad de Buenos Aires, Buenos Aires.

Delgado-Álvarez, M. C., Sánchez, G. M. C. \& Fernández-Dávila, J. P. A. (2012). Atributos y estereotipos de género asociados al ciclo de la violencia contra la mujer. Universitas Psychologica, 11 (3), 769-777.

Fiscalía General del Estado. (2016). Femicidio. Análisis penológico (1). Recuperado de https://www.fiscalia.gob.ec/images/publicaciones/femicidiopc.pdf

Franke, D., \& Ojeda, P. (2013). Historiografía e historia de mujeres: estrategias para su inclusión en los procesos de enseñanza-aprendizaje en la educación media chilena. Estudios Pedagógicos XXXIX, (1), 361-375. 
Frías, S. (2014). Ámbitos y formas de violencia contra mujeres y niñas: Evidencias a partir de las encuestas. Acta Sociológica, (65), 11-36.

Jorge, Ana María., (2016). Violencia de Género y comunicación. Sociedad latina de comunicación. Cuadernos de Artesanos, 109. Laguna (Tenerife). 11-33.

García, R., Aguaded, J., \& Rodríguez, A. (2014). Propuesta de alfabetización mediática ante los estereotipos de género en los medios de comunicación. Resultados de la valoración de "Rostros de Mujer". Prisma Social, (13), 579-609.

Gómez, E., Medina, P., \& Ramon, X. (2017). La presencia invisible de la mujer deportista en la prensa deportiva española. Análisis de las portadas de Marca, As, Mundo Deportivo y Sport (2010-2015). Estudios sobre el Mensaje Periodístico, 23(2),

793-810. doi: http://dx.doi.org/10.5209/ESMP.58016

Guarderas, P. (2016). Silencios y acentos en la construcción de la violencia de género como un problema social en Quito. Íconos, (55), 191-213. doi: http://dx.doi.org/10.17141/iconos.55.2016.1700

Menéndez, M. (2014). Retos periodísticos ante la violencia de género. El caso de la prensa local en España. Nueva época, (22), 53-77.

Metz Galán, O. (2016). Construcción de estereotipos masculinos y femeninos en la televisión dominicana: diferencias en la percepción de roles. Razón y Palabra. Vol 20 núm 93. Abril -junio 2016, pp 300-319.

Maqueda, M. (2006). La violencia de género. Entre el concepto jurídico y la realidad social. Revista Electrónica de Ciencia Penal y Criminología, (08-02), 02:1-02:13. Recuperado de http://www.cienciaspenales.net/files/2016/09/ 2violencia_genero_maqueda.pdf

Zurbano, B., \& Liberia, I. (2014) Revisión teórico-conceptual de la violencia de género y de su representación en el discurso mediático. Una propuesta de resignificación. Zer, 19 (36), 121-143. 
